\title{
Correction to: Acute Toxicity of Nickel to Daphnia magna: Validation of Bioavailability Models in Japanese Rivers
}

\author{
Hiroyuki Mano (D) Naohide Shinohara
}

Published online: 28 May 2021

(C) Springer Nature Switzerland AG 2021

Correction to: Water Air Soil Pollut (2020) 231: 459

https://doi.org/10.1007/s11270-020-04842-1

The original publication of this article (doi: $10.1007 /$ s11270-020-04842-1) contained the following errors:

(1) In page 4, section 2.2 "Test Species and Stock Culture," the units of the numbers "1.93 (1.632.22) $\mu \mathrm{g} / \mathrm{L}$ " and "0.81 (0.71-0.92) $\mu \mathrm{g} / \mathrm{L}$ " were wrong. The units should have been "mg/L" instead of " $\mu \mathrm{g} / \mathrm{L} . "$

(2) In Online Resource 2, the last sentence of the second paragraph in the Results section "The estimated values (95\% confidence intervals) of dissolved-nickel $\mathrm{EC}_{50}$ were 1.93 (1.63-2.22) $\mu \mathrm{g} / \mathrm{L}$ for the moderately hard water culture and $0.81(0.71-0.92) \mu \mathrm{g} / \mathrm{L}$ for the soft water culture" should be read as "The estimated values $(95 \%$ confidence intervals) of dissolved-nickel $\mathrm{EC}_{50}$ were $1.93(1.63-2.22) \mathrm{mg} / \mathrm{L}$ for the moderately hard water culture and $0.81(0.71-0.92) \mathrm{mg} / \mathrm{L}$ for the soft water culture."

(3) In Online Resources 2 and 4, the unit was incorrectly written in the $x$-axis labels in Fig. 1. The unit should have been " $\mathrm{mg} / \mathrm{L}$ " instead of " $\mu \mathrm{g} / \mathrm{L}$." The correct figures are reproduced on the following pages. 
Fig. 1 in Online Resource 2

a)

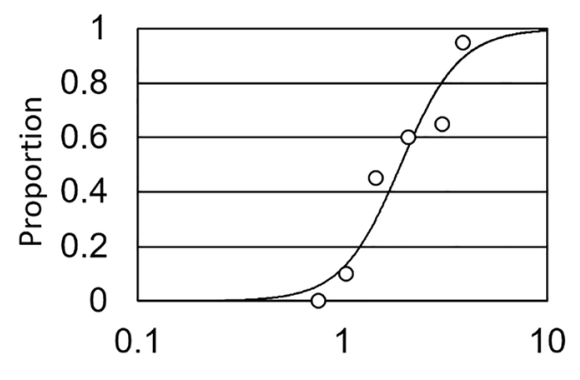

Measured concentration of dissolved nickel (mg/L) b)

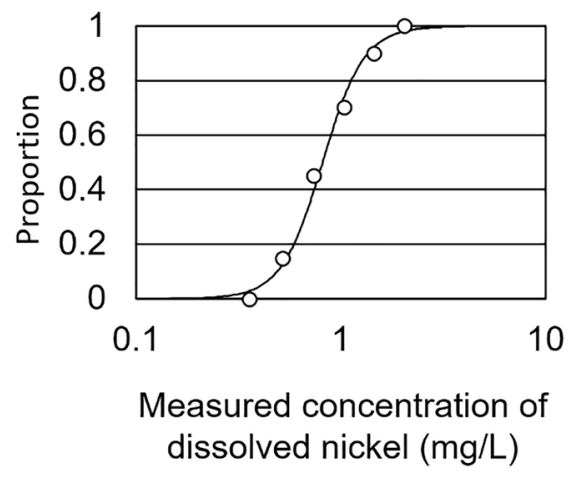


Fig. 1 in Online Resource 4

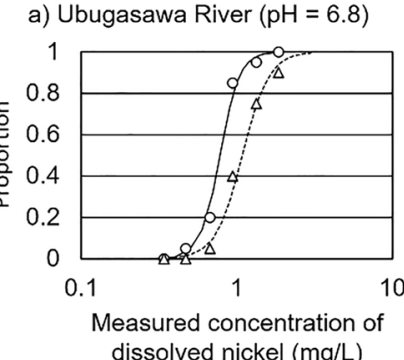

c) Yamaguchi River $(\mathrm{pH}=6.8)$

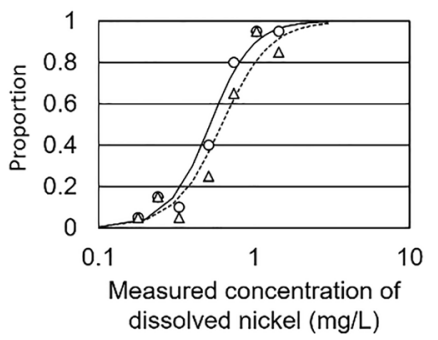

e) Isumi River ( $\mathrm{pH}=7.4)$

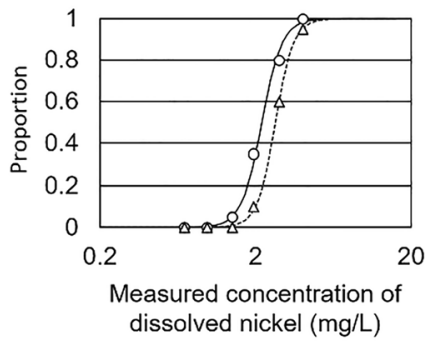

g) Iwasome River $(\mathrm{pH}=7.4)$

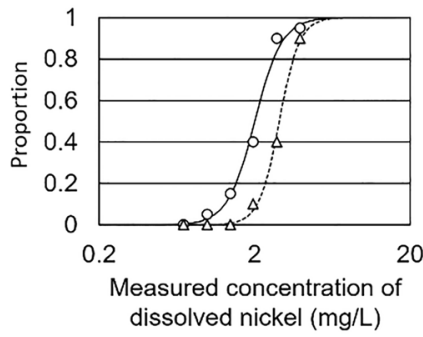

i) Kabura River $(\mathrm{pH}=7.4)$

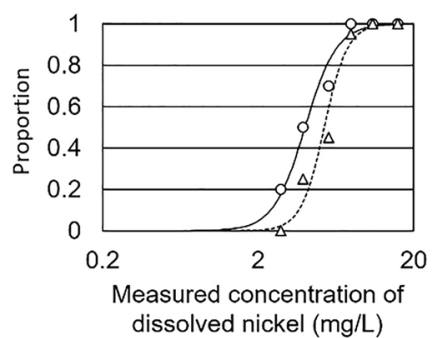

b) Ubugasawa River $(\mathrm{pH}=7.4)$

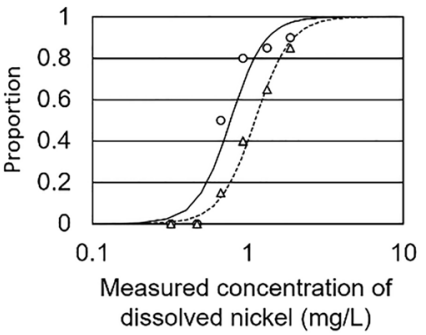

d) Yamaguchi River $(\mathrm{pH}=7.4)$
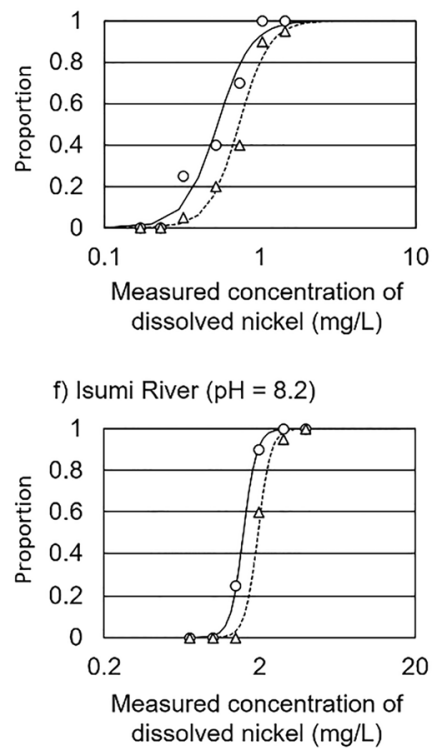

h) Iwasome River $(\mathrm{pH}=8.2)$

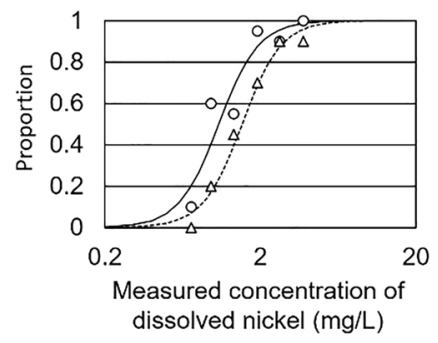

j) Kabura River $(\mathrm{pH}=8.2)$

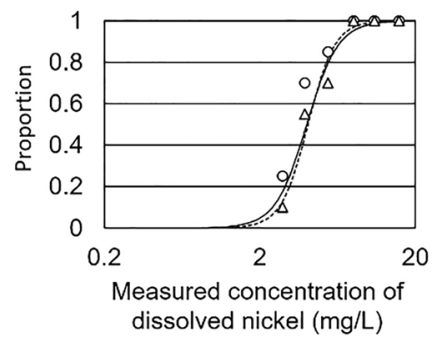


Publisher's Note Springer Nature remains neutral with regard to jurisdictional claims in published maps and institutional affiliations. 